\title{
Coordinated stable auroral red arc observations: Relationship to plasma convection
}

\author{
J. C. Foster and M. J. Buonsanto \\ Atmospheric Sciences Group. Massachusetts Institute of Technology Haystack Observatory, Westford
}

\author{
M. Mendillo and D. Nottingham \\ Astronomy Department, Boston University, Boston, Massachusetts
}

\author{
F. J. Rich and W. Denig \\ Geophysics Division, Phillips Laboratory, Hanscom Air Force Base, Massachusetts
}

\begin{abstract}
During the March 20-22, 1990, magnetic storm, Millstone Hill radar and DMSP satellite observations detailed the conditions surrounding the occurrence of a SAR arc which was observed continuously through an 8-hour interval from dusk till past midnight in the North American sector. All-sky imaging with a 630.0-nm imager continually monitored the two-dimensional position and magnitude of the SAR arc emission while radar scans and satellite overflights measured magnetospheric inputs and ionospheric response. The arc was colocated with a deep, narrow plasma trough and a region of enhanced westward plasma convection of similar width situated immediately equatorward of the low-latitude extent of plasma sheet particle precipitation. A region of low-energy ion precipitation was observed at the equatorward edge of the SAR arc during a period of spatial/temporal coincident satellite/radar observations near the Millstone Hill longitude. The width of the SAR arc and related phenomena was of the order of $2^{\circ}$, and the $\sim 200-R$ emission was associated with an electron temperature of $\sim 3500^{\circ} \mathrm{K}$ and a $10 \times$ reduction of plasma density at an altitude of $450 \mathrm{~km}$. The best-fit model for the emission intensities of both the SAR arc and the background airglow suggests that either the electron temperature at the center of the SAR arc was somewhat higher than observed by the radar $\left(\sim 4000^{\circ} \mathrm{K}\right)$, or the neutral densities, $\left[\mathrm{O}_{2}\right]$ and $[\mathrm{O}]$, were increased by factors of 2 and 4 , respectively, with respect to the MSIS values. The ionospheric trough and a colocated region of enhanced sunward convection $\left(500-1700 \mathrm{~m} \mathrm{~s}^{-1}\right)$ were observed in conjugate hemispheres throughout the local time range 18 - 02 MLT. The convection feature seen in association with the SAR arc had many of the characteristics of a subauroral ion drifts (SAID) event; we report here the first longduration observations of a colocated SAID/SAR arc event. A narrow ionospheric trough developed during the interval when the SAID velocity was $>1000 \mathrm{~m} \mathrm{~s}^{-1}$ and was accompanied by a weak (100 R) 630.0-nm emission. As the velocity fell to $700 \mathrm{~m} \mathrm{~s}^{-1}$, the density in the trough recovered somewhat, and the arc intensity rose to $\sim 300 \mathrm{R}$ above background. This brighter period of the SAR arc occurred within a fossil trough/SAID. We conclude that there is a close spatial and temporal association among these three types of subauroral low-altitude phenomena - the SAR arc, the SAID event. and the fossil (convection-related) trough - and that this is indicative of the interrelationship of the magnetospheric processes and boundaries which are involved in their formation.
\end{abstract}

\section{Introduction}

Stable auroral red (SAR) arcs are observed optically equatorward of the region of plasma sheet induced emission (diffuse aurora) and auroral precipitation signatures (discrete arcs). Typically, they are first seen in the dusk sector and can persist until dawn, moving to lower magnetic latitudes near midnight. The 630.0-nm emission characteristic of this phenomenon has been suggested to be related to the effects of a downward heat flux near the plasmapause and the inner edge of the ring current particle population [Hoch and Lemaire, 1975]. Low-energy particle precipitation can also contribute to the emission level during disturbed conditions. Kozyra et al. [1987] have found that Coulomb collisions

Copyright 1994 by the American Geophysical Union.

Paper number 93JA03140.

0148-0227/94/93JA-03140\$05.00 between ring current heavy ions and thermal electrons can provide the energy source for SAR arcs. Slater et al. [1987] observed precipitating fluxes of electrons of $<10 \mathrm{eV}$ associated with SAR arcs, with no discernible enhancement at or above $20 \mathrm{eV}$. Mendillo et al. [1987] presented the first simultaneous 630.0-nm images and incoherent scatter radar observations of a SAR arc. Depleted electron density and elevated electron temperature $\left(\log N e \times 4.5 \mathrm{~cm}^{-3}\right.$ and $T e=2000^{\circ} \mathrm{K}$ at $440 \mathrm{~km}$ altitude) were observed in association with the faint $(<100 \mathrm{R})$ postmidnight SAR arc. However, modeling of the emission from the observed ionospheric parameters failed to yield the emission levels observed, suggesting that a small precipitation-induced component may well occur.

In this paper we present radar, optical, and satellite observations of the conditions surrounding the occurrence of a SAR arc which was observed continuously through an 8-hour interval from dusk till after midnight in the North American sector. The arc was colocated with a deep, narrow plasma trough and a region of enhanced 
westward plasma convection of similar width situated immediately equatorward of the low-latitude extent of plasma sheet particle precipitation. The associated region of westward (sunward) convection had many of the characteristics of the subauroral ion drifts (SAID) phenomenon and was clearly separate from the usual, more poleward, region of auroral sunward convection, similar to events reported in the study by Yeh et al. [1991]. Radar, optical, and satellite observations in the vicinity of SAID during an intense geomagnetic storm also have been reported by Providakes et al. [1989].

\section{Instrumentation}

The Millstone Hill Observatory is located in eastern Massachusetts at $42.6^{\circ} \mathrm{N}$ latitude, $288.5^{\circ} \mathrm{E}$ longitude $\left(55^{\circ} \Lambda\right)$ and is well situated to observe effects related to magnetosphere-ionosphere coupling near the plasmapause, the inner edge of the ring current, and the ionospheric trough. The Millstone Hill UHF incoherent scatter radar is used to monitor ionospheric features and response over the altitude range $150 \mathrm{~km}$ to $1000 \mathrm{~km}$ with a typical altitude/ spatial resolution of $50 \mathrm{~km}$. Its fully steerable $46-\mathrm{m}$ antenna provides wide-ranging spatial coverage, spanning $30^{\circ}$ of latitude and 4 hours of local time at $F$ region heights. The equatorward offset of the north geomagnetic pole nearly along the Millstone Hill meridian brings high-latitude and auroral phenomena into the observatory's near field of view during disturbed conditions and particularly during magnetic storms.

A CEDAR all-sky optical imaging system, designed and operated by Boston University, is colocated with the radar at Millstone Hill and routinely maps the 630.0-nm aurora and airglow over a $2000-\mathrm{km}$-radius region centered on the site. A low light level sensitivity ( $\sim 3200$ Rayleigh seconds for a $S / N=5$ at $\sim 100 \mathrm{R}$ signal) and CCD digital readout provide a flexible capability for coordinated multidiagnostic studies of the subauroral ionosphere [Baumgardner and Karandanis, 1984; Mendillo et al., 1987, $1989 \mathrm{~b}]$. On the night of March 22, 1990, the imager provided redline emission maps every $3 \mathrm{~min}$ throughout the duration of the SAR arc event.

The Defense Meteorological Satellite Program (DMSP) satellites F8 and F9 are in sun-synchronous polar orbits at $\sim 830 \mathrm{~km}$ altitude and provide high-resolution in situ observations of vertical and horizontal plasma drift and plasma density as well as precipitating ion and electron parameters over the energy range $30 \mathrm{eV}$ to $30 \mathrm{keV}$. The DMSP instruments have been described by Greenspan et al. [1986] and Rich and Hairston [1994]. Twenty-channel partcle spectra were obtained with 1 -s temporal resolution $(\sim 8 \mathrm{~km}$ spatial), drift meter velocities with $1 / 6 \mathrm{~s}(\sim 1 \mathrm{~km})$ resolution, and density at $1 / 24 \mathrm{~s}(0.32 \mathrm{~km})$. Because of the wide spatial coverage of the Millstone Hill radar and the CEDAR imager, two or three consecutive orbits of the DMSP satellites provide overflights within or near their field of view. During the course of this event, the F8 satellite provided latitudinal cuts across the SAR arc and the auroral region between 17 MLT and 21 MLT while F9 provided coverage between 20 MLT and 24 MLT.

\section{Observations}

The March 22, 1990, SAR arc event occurred during the extended recovery phase of a large magnetic storm which had its most significant intensification near 2330 UT on March 20. The $K p$ index reached $7+$ at the time of the major intensification and was 4+ through the SAR arc interval on March 22. Radar observations spanned the entire storm, March 16-23, 1990, and an overview of the experiment and observations has been presented by Buonsanto et al. [1992a].

\section{Optical Characteristics}

The Boston University imager detected a faint mid-latitude red arc amid the twilight glow as observations began near 0000 UT on March 22 and continuously monitored that feature as it slowly descended in latitude until at least 0800 UT. Plate 1 presents the 630.0-nm image observed at 0340 UT (2240 MLT), the time of a DMSP F9 overflight which will be discussed in detail below. The image has been background corrected, with each pixel mapped into geographic latitude and longitude coordinates using a $400-\mathrm{km}$ emission altitude. The SAR arc is magnetic latitude aligned and offset by $6^{\circ}$ from the equatorward edge of the much stronger diffuse aurora seen in the north.

Figure 1 presents a composite picture of the magnetospheric and ionospheric features associated with this SAR arc. In Figure la are presented in situ density measurements from the F9 satellite, during its overflight along the $-75^{\circ}$ meridian, which showed a $>5 x$ decrease in a $2^{\circ}$-wide trough colocated with the arc. The digital 630.0-nm image has been sampled along the $-75^{\circ}$ meridian at the time of the satellite overflight, and these data are presented in Figure $1 \mathrm{~b}$. The red-line emission had a maximum intensity of $210 \mathrm{R}$ above background, was sharply peaked at $43.5^{\circ}$, and spanned $2^{\circ}$ of geodetic latitude. An increase to the instrument saturation level ( $>400 \mathrm{R}$ ) was associated with the bright aurora to the north.

\section{Relationship to Sunward Convection}

High-resolution ion drift meter data, presented in Figure 1d, show upward velocities of $50 \mathrm{~m} \mathrm{~s}^{-1}$ immediately equatorward of the arc and downward drift of the same magnitude associated with the arc itself. The horizontal (E-W) drift was dramatic, with the SAR arc and density trough situated within a $3^{\circ}$-wide region of westward (sunward) convection with a maximum velocity of $550 \mathrm{~m} \mathrm{~s}^{-1}$ (in the inertial reference frame, corrected for corotation) on the immediate equatorward edge of the arc. Sunward convection was associated with the arc throughout the event. At 0340 UT, the arc was located immediately poleward of the region of most intense $\left(0.8 \mathrm{~V} \mathrm{~km}^{-1}\right)$ poleward gradient of the poleward directed electric field, where the westward convection velocity increased by $400 \mathrm{~m} \mathrm{~s}^{-1}$ over a distance of $\sim 25 \mathrm{~km}$. Taking the ionospheric current to be divergence free, and for an assumed Pedersen conductance of $1 \mathrm{mho}$, an inward directed (region 2) field-aligned current density of $0.8 \mu \mathrm{A} \mathrm{m}^{-2}$ is calculated for this region. We also note that a nonuniform velocity field above Millstone Hill was suggested by Buonsanto et al. [1992b] as the most likely cause of the large difference between incoherent scatter and Fabry Perot interferometer-derived neutral winds on the night of March 22, 1990. The present results confirm the existence of this nonuniform velocity field.

\section{Particle Signatures}

Precipitating particle observations revealed no electron precipitation at energies between $30 \mathrm{eV}$ and $30 \mathrm{keV}$ associated with the SAR arc (data not shown). Slater et al. [1987] have reported an enhancement of electron precipitation at energies of $<10 \mathrm{eV}$, but no increase at $20 \mathrm{eV}$ or above, during DE 2 overflights of SAR arcs. Such a soft electron flux would lie below the energy threshold of the DMSP detectors. A region of low-energy ion precipitation $(<800$ $\mathrm{eV}$ ) was observed immediately equatorward of the SAR arc (Figure 2c) and appears to mark the equatorward extent of the magnetospheric ion population. Flectron and ion precipitating particle 


\section{BOSTON UNIVERSITY
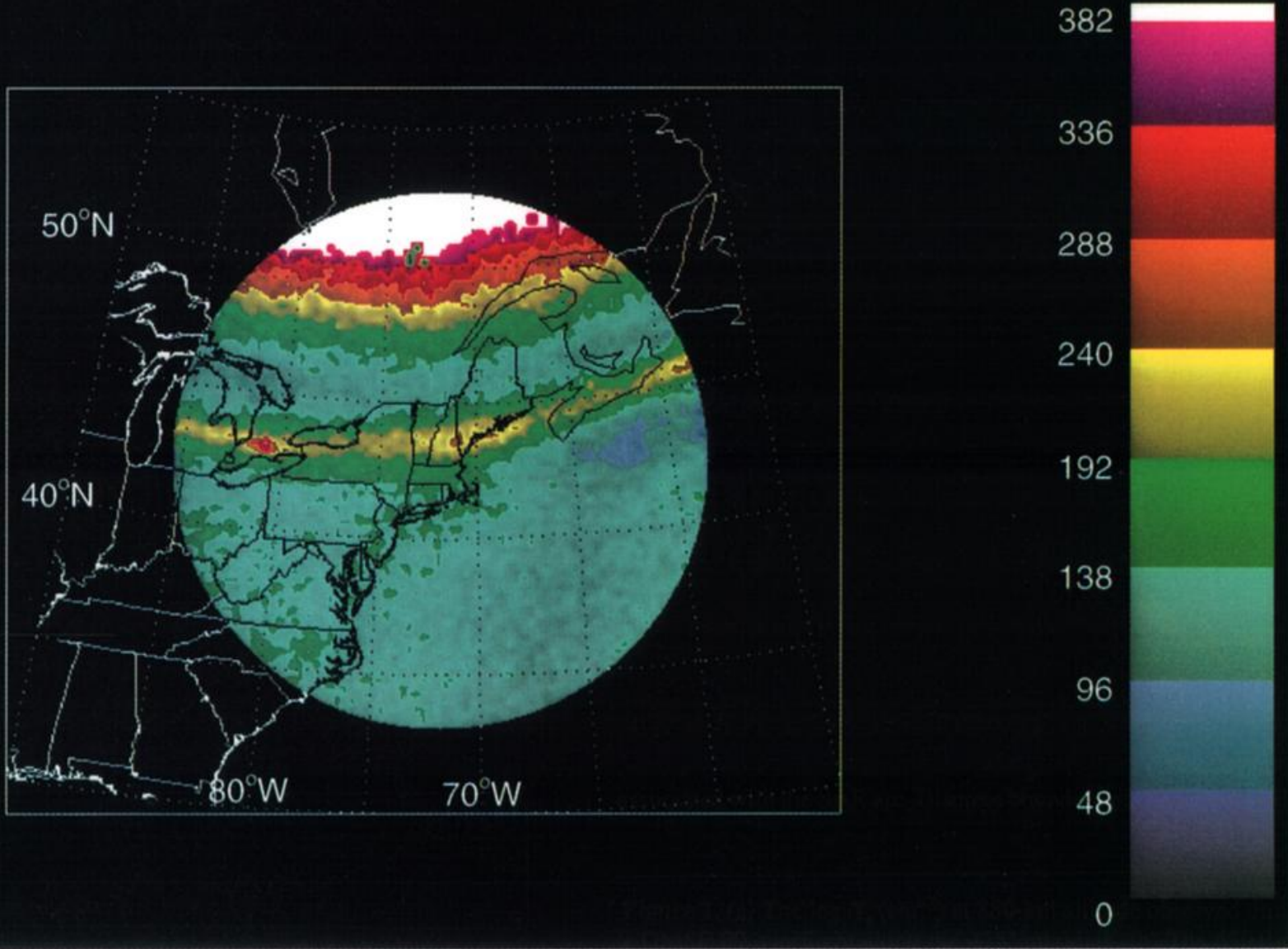

Plate 1. A 630.0-nm image of a magnetic-latitude-aligned SAR arc lying equatorward of the region of auroral emission at the time of a DMSP F9 overflight on March 22, 1990.
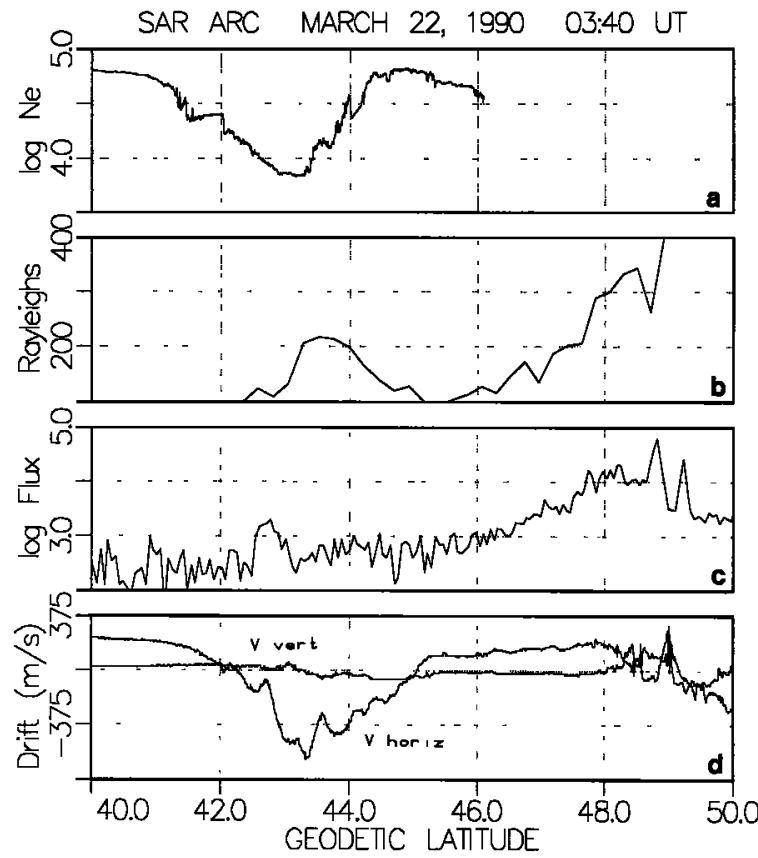

spectrograms for the DMSP F9 overflight of the SAR arc at 0340 UT on March 22, 1990, are presented in Plate 2. The ion drift meter velocities (in the noncorotating frame of reference) are shown at the bottom and can be used for reference to the SAR arc features shown in Figure 1. Ion drift meter data are shown in the lower panel, and the isolated sunward convection feature just before 13200 UT s identifies the location of the SAR arc, as detailed in the preceding figure. Strong ion and electron precipitation and enhanced auroral luminosity are seen associated with the more poleward region of sunward convection, but all vestiges of an enhanced electron flux $(>20 \mathrm{eV})$ end at the poleward boundary of the convection feature associated with the SAR arc. Discrete boundary plasma sheet (BPS)

Figure 1. (a) The $\log N_{e}\left(\mathrm{~cm}^{-3}\right)$ at $880-\mathrm{km}$ altitude observed during a DMSP F9 overflight along the $-75^{\circ}$ meridian. (b) The $630.0-\mathrm{nm}$ intensity at $-75^{\circ}$ longitude observed with the Millstone Hill imager. (c) DMSP integral ion precipitating flux (particles $\mathrm{cm}^{-2} \mathrm{~s}^{-1} \mathrm{sr}^{-1} \mathrm{eV}^{-}$ 1), $20-800 \mathrm{eV}$. (d) Drift meter horizontal and vertical velocity. The SAR arc was centered at $43.5^{\circ}$, within a deep ionospheric trough and immediately poleward of a region of low-energy ion precipitation and the maxinum of the westward plasma convection. 


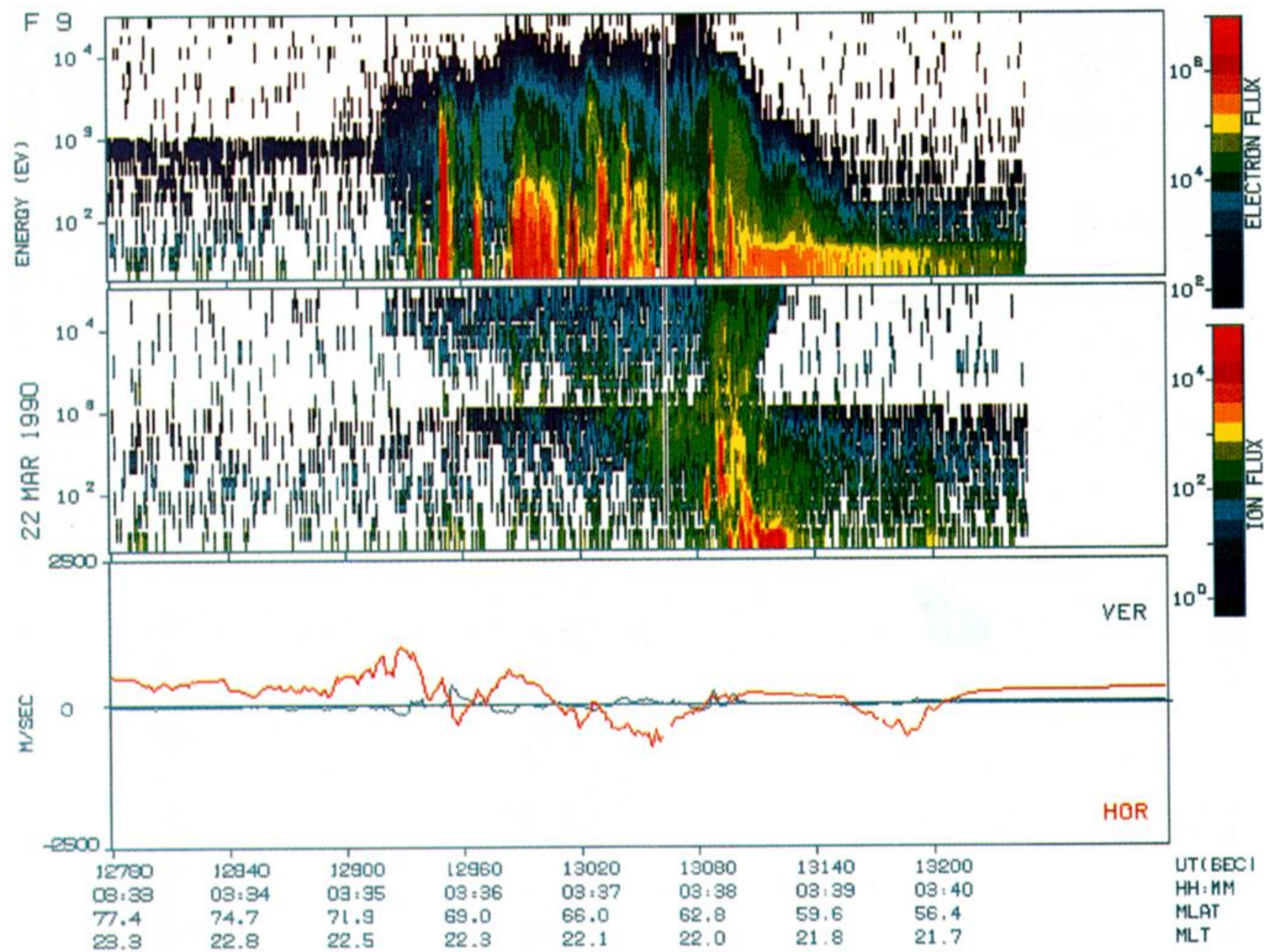

Plate 2. Data obtained by DMSP F9 on March 22,1990. (Top) Spectrogram of precipitating electron data; (middle) precipitating ion data; (bottom) components of the thermal ion bulk flow perpendicular to the satellite path and in the horizontal plane (positive antisunward) and vertical plane (positive upward). The separate region of sunward convection near $57^{\circ}$ magnetic latitude marks the location of the SAR arc (see Figure 1).

electron precipitation extends from the equatorward extent of the auroral region of sunward convection $\left(62^{\circ} \Lambda\right)$ to the sunward/antisunward velocity reversal near $69^{\circ} \Lambda$, where intense "inverted- $V$ " electron precipitation is seen. Diffuse central plasma sheet (CPS) precipitation extends from $62^{\circ} \Lambda$ to $59^{\circ} \Lambda$, the poleward extent of the sunward convection associated with the narrow trough and SAR arc. The faint low-energy ion precipitation feature at the equatorward edge of the SAR arc is seen at $13200 \mathrm{UT} s\left(56.4^{\circ} \Lambda\right)$. The data of Figure 1c were obtained by integrating the ion flux between 20 $\mathrm{eV}$ and $800 \mathrm{eV}$.

\section{Ionospheric Characteristics}

Incoherent scatter radar elevation scans revealed the latitude/ altitude structure of the ionospheric features associated with this SAR arc. Figure 2 presents radar observations of the ionospheric trough (Figure $2 \mathrm{a}$ ) and electron temperature enhancement (Figure 2b) which accompanied the arc, as observed along the Millstone Hill meridian ( $4^{\circ}$ east of the DMSP meridian) at the time of the satellite overflight. The latitude profile of the red-line intensity is repeated in Figure $2 d$ to indicate the alignment of the temperature and density features with the SAR arc. The radar scan data show a density trough at all heights at the latitude of the arc and a corresponding increase in electron temperature to $>2500^{\circ} \mathrm{K}$ at the $F$ region peak height near $480 \mathrm{~km}$. Figure2c superimposes the iono- spheric convection velocity measurements (in the corotating frame) made with the DMSP drift meter (solid line) and with the Millstone Hill radar (discrete points) during an azimuth scan to the west of the satellite meridian. Because of the longitudinal separation of the velocity data sets, and the more poleward location of the trough/ velocity feature at the $265^{\circ}$ meridian of the radar azimuth scan, the Millstone Hill velocity data have been shifted equatorward by $1.5^{\circ}$ in order to be aligned with similar features near the $285^{\circ}$ longitude of the other data sets. The magnitude and spatial breadth of the sunward convection region associated with the trough and SAR arc are nearly identical in the satellite and radar observations, as is the separation from a second sunward convection region associated with auroral latitude phenomena at higher latitude $\left(50^{\circ}\right)$. The close relationship among the location of the SAR arc, the trough, and the isolated, more equatorward, region of westward convection, as seen in Figure 2, persisted for the course of the event.

The radar scan data provided continuous coverage of the evolution of the ionospheric parameters in the vicinity of the SAR arc. Figure 3 summarizes the latitude/time development of the westward velocity and electron density and temperature at an altitude of $450 \mathrm{~km}$, the peak of the SAR arc emission (see Figure 6 and related discussion, below). Both the separate, equatorward region of westward convection (Figure 3a) and the temperature enhancement (Figure 3c) associated with the trough (Figure 3d) moved slowly to 

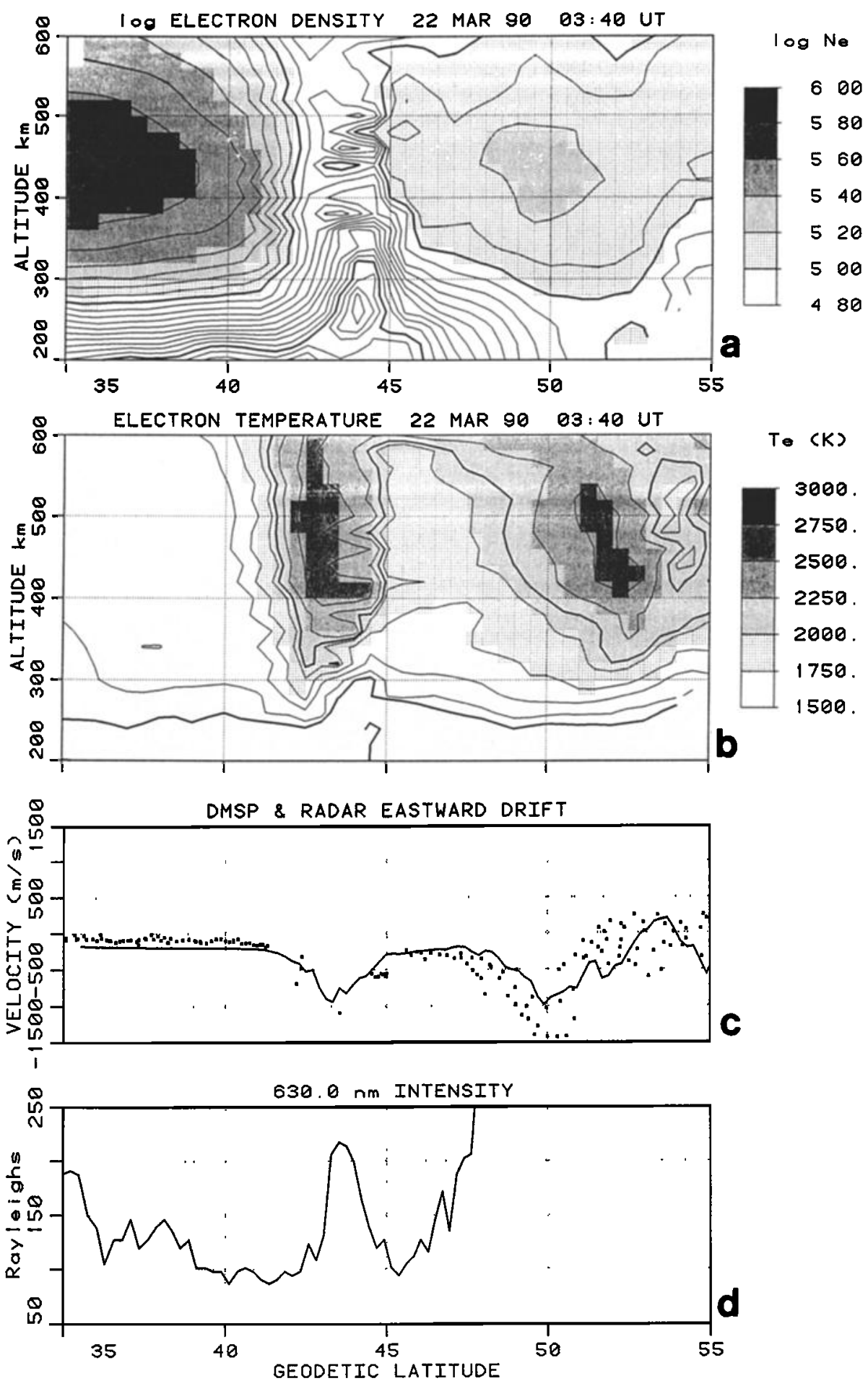

Figure 2. (a) and (b) Millstone Hill Radar elevation scan observations of the electron density trough and colocated electron temperature enhancement. (c) DMSP F9 drift meter horizontal velocity (line) and radar convection velocity observations (points) showing a discrete region of enhanced westward convection associated with the trough and SAR arc. (d) The 630.0-nm intensity defines the SAR arc centered at $43.5^{\circ}$.

lower latitude as the evening progressed. In order to maintain the maximum spatial resolution of the radar convection velocity measurements, the data displayed in Figure 3 are individual line-ofsight velocity observations taken while the antenna scanned at low elevation angle from NW to SW. The structure and evolution of the equatorward convection feature, evident in Figure 3a, is similar to that reported by Yeh et al. [1991]. Figure 3b displays the $630.0-\mathrm{nm}$ intensity sampled by the imager along the $285^{\circ}$ meridian. The SAR arc is seen to emerge from the background at sunset (0100 UT) and to lie near $43^{\circ}$ throughout the interval. Maximum SAR arc intensity occurred during a 2 -hour interval centered near 0500 UT.

\section{Conjugate Signature}

DMSP observations of a narrow trough in the southern hemisphere, also associated with a region of sunward convection, provide evidence for the conjugacy of the features reported above. 

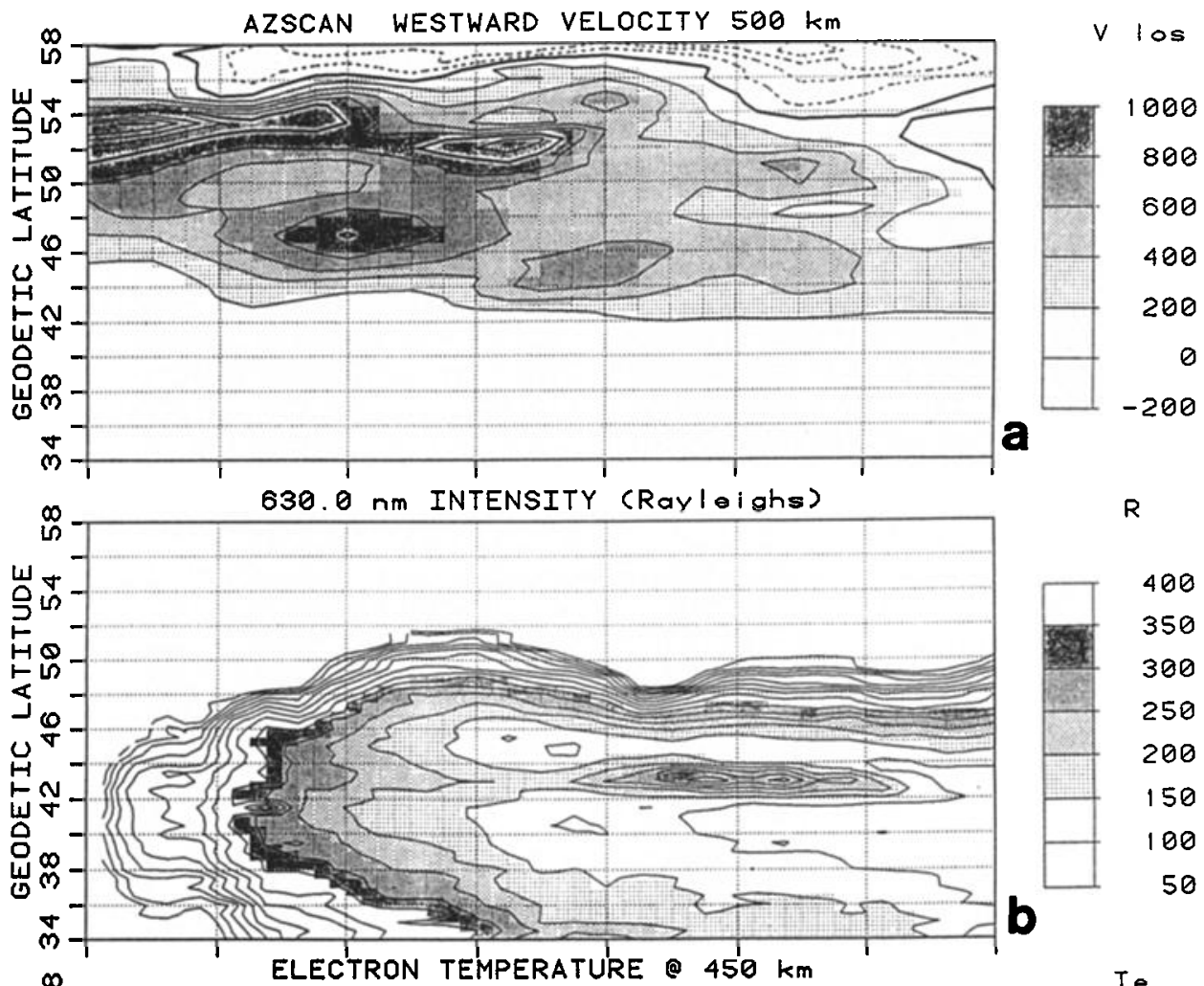

R
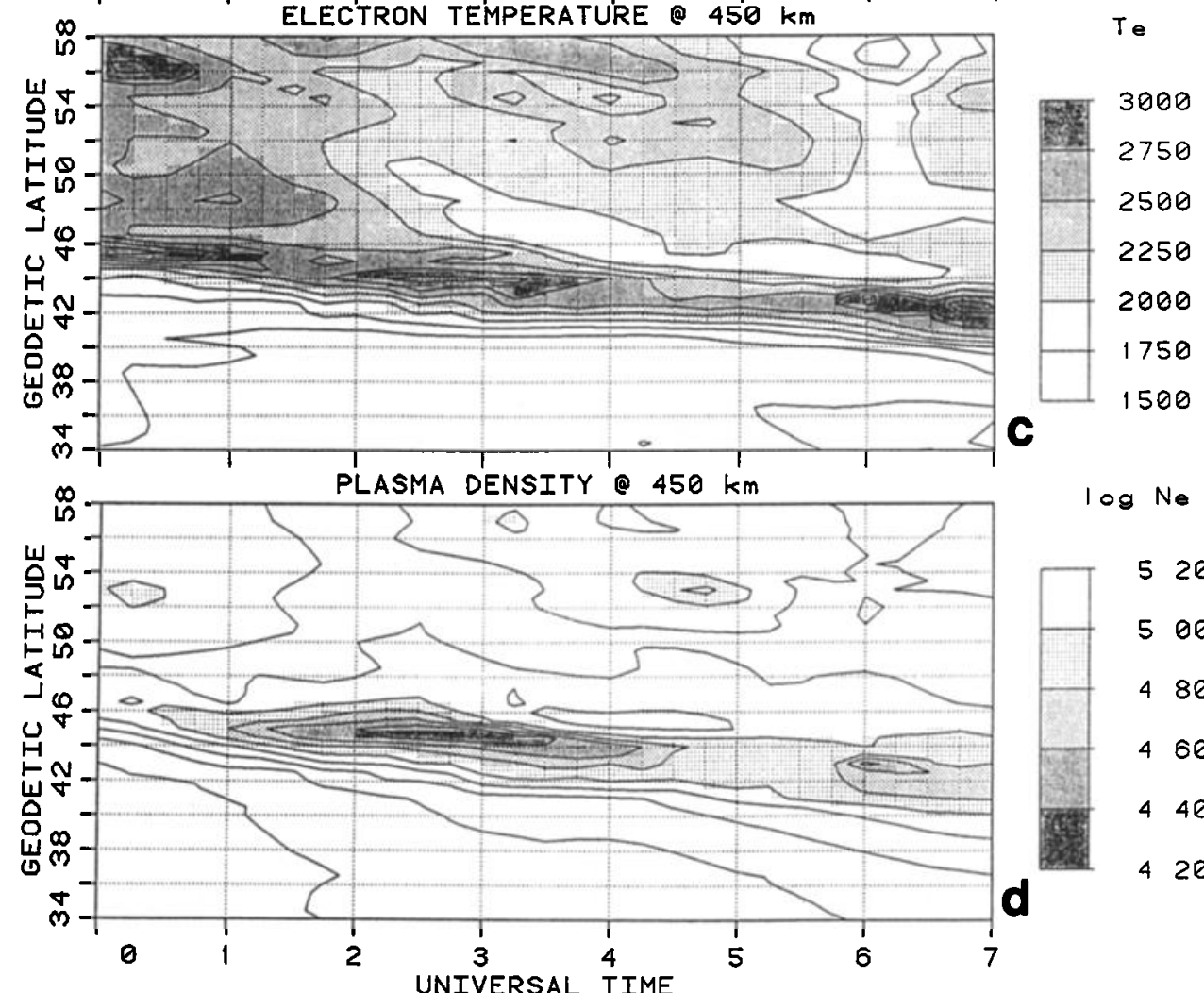

520

500

480

460

440

420

Figure 3. Radar scan maps of (a) westward velocity and (c) $T_{e}$ showing discrete, trough-related features descending in latitude through the March 22, 1990, event. Also shown are (d) the location of the density trough and (b) the latitude extent of the SAR arc emission feature. Two peaks in the westward convection velocity, separated by $\sim 5^{\circ}$ in latitude, were seen throughout most of the event. The SAR arc was associated with the more equatorward of these convection features.

Thirteen satellite crossings of the trough/convection feature were recorded in the two hemispheres by the DMSP F8 and DMSP F9 satellites. Unfortunately, we do not have optical data from the southern hemisphere to confirm the conjugacy of the SAR arc itself. We have shown, above, that the SAR arc was clearly associated with a narrow, distinct, mid-latitude trough. Figure 4 presents the northern and southern hemisphere positions of the equatorward and poleward boundaries of the mid-latitude trough observed during this event. Because of the large difference in the relationship between geographic and magnetic latitude in the two hemispheres, 

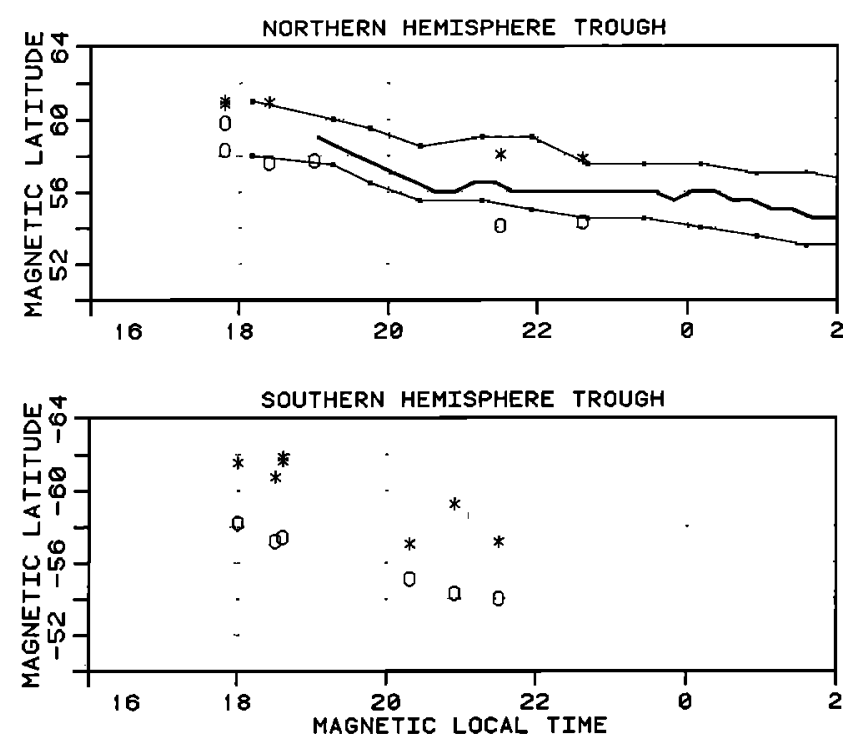

Figure 4. Conjugate DMSP observations of the boundaries of the narrow, equatorward trough (points), trough boundaries observed with the Millstone Hill Radar (thin lines), and SAR arc center position determined by the $630.0-\mathrm{nm}$ imager (heavy line). The narrow $F$ region trough, which was associated with the SAR arc in the northern hemisphere, was a magnetically conjugate phenomenon.

the boundaries are plotted in magnetic latitude and local time coordinates, and in these coordinates, the trough position in the two hemispheres is seen to be very similar. The equatorward trough boundaries observed by the DMSP satellite are indicated by circles. while the poleward boundaries are shown by asterisks. The boundaries of the trough seen by the Millstone Hill radar (light lines) are indicated on the northern hemisphere plot and agree closely with the satellite observations. The heavy curve indicates the center of the SAR arc emission observed at 15-min intervals by the red-line imager at Millstone Hill. The fact that the width and location of the trough are geomagnetically conjugate gives further evidence that the trough, in this instance, is a convection-related feature.

\section{Relationship of SAR Arc Emission to Ionospheric Parameters}

The interrelationship of the ionospheric parameters observed in the trough with the 630.0-nm emission intensity is shown in Figure 5. Ion velocity observed in either hemisphere by the DMSP satellites is shown by the heavy curve in the top panel, while the radar observations of the westward convection in the trough are indicated by diamonds. At the beginning of the event, the velocity exceeded $1000 \mathrm{~m} \mathrm{~s}^{-1}$ intermittently over a 3-hour period. Red-line emission intensity was low while the velocity was high and then brightened considerably between 0400 UT and 0600 UT. Electron density at $450 \mathrm{~km}$ fell rapidly as the trough developed during the interval of strong convection. Density depletion and trough formation due to the effects of enhanced recombination in the presence of ion convection has been predicted theoretically by Schunk et al. [1976] and observed from Millstone Hill by Providakes et al. [1989] and Buionsanto et al. [1992a]. The relationship of trough formation and SAID has been discussed by Anderson et al. [1993]. In the case discussed here, trough density increased by a factor of 2 after 0300 UT when the velocity fell below $1000 \mathrm{~m} \mathrm{~s}^{-1}$. The higher velocities observed early in the event could have contributed to trough formation, leaving a longitudinally extended, conjugate fossil trough [Evans et al., 1983] within which the SAR arc was located. The active processes responsible for the equatorward region of sunward convection continued, however, as evidenced by the velocities of $500 \mathrm{~m} / \mathrm{s}$ to 800 $\mathrm{m} / \mathrm{s}$ observed by the radar and the drift meter within the trough for the remainder of the event.

Ionospheric electron temperature observed with the Millstone Hill radar in the vicinity of the SAR arc emission is presented in the lower panel of Figure 5. Radar coverage across the region of the narrow SAK are was not continuous. Discrete samples with the narrow-beam antenna were centered at $42.8^{\circ}$ and $44.3^{\circ}$ latitude (at 450 $\mathrm{km}$ altitude), leaving a gap in the coverage near $43.5^{\circ}$. Electron temperature at $450 \mathrm{~km}$ altitude increased to $3500^{\circ} \mathrm{K}$ at the time of the initial brightening of the arc after 0230 UT. The observed electron temperature decreased through the interval 0300 UT to $0500 \mathrm{UT}$, although the arc intensity increased to over $300 \mathrm{R}$ above background during that time. However, the center of the arc moved equatorward from $44^{\circ}$ to $42.5^{\circ}$ during that same interval, and it is probable that the radar observations do not reflect the true temperature associated with the arc emission at that time. A maximum electron temperature of $4000^{\circ} \mathrm{K}$ was observed near 0600 UT when the arc was intersected more closely by the radar beam. It is an unfortunate coincidence that the SAR arc lay in the narrow gap of the radar coverage at the time of its maximum intensity.

\section{Modeling the SAR Arc Emission}

A long-term ( $\sim 4$ years) study of SAR arc occurrence frequency, morphology patterns, and sase study modeling has recently been completed (M. Mendilio et al., manuscript in preparation, 1994). The event of March 22, 1990, while included in the statistics, was not modeled in that earlier study. Our modeling of this event is reported below. The details of the modeling approach will not be
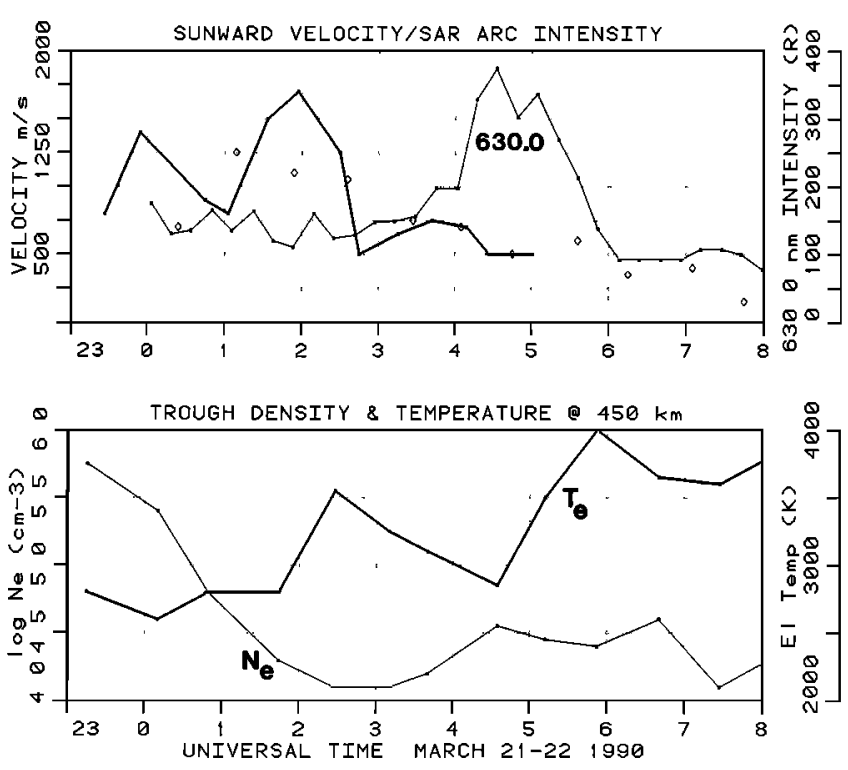

Figure 5. (Top) SAR arc intensity (thin line), DMSP F8 and F9 observations of the convection velocity magnitude within the narrow trough in conjugate hemispheres (heavy line), and Millstone convection velocity within the trough (diamonds). The SAR arc emission was most intense after the velocity fell below $1000 \mathrm{~m} \mathrm{~s}^{-1}$. (Bottom) Minimum electron density (thin line) and $T_{e}$ within trough (heavy line) at $450-\mathrm{km}$ altitude observed by the Millstone Hill radar. The narrow SAR arc lay between radar observing positions near $0500 \mathrm{UT}$, the time of maximum arc intensity, and the radar data may not represent the true density and temperature associated with the arc at that time. 
repeated here, except to note that extreme care was used in all aspects of the calibration and background subtraction due to the preponderance of faint SAR arcs encountered, as typified by the March 22 event. The SAR arc formulation of Rees and Roble [1975] was adopted, with updated reaction rates and emission parameters; the MSIS-86 [Hedin, 1987] model was used to calculate the neutral concentration profiles needed for the calculation, while Millstone radar results were used for $N_{e}(h), T_{e}(h)$, and $T_{i}(h)$. Separate calculations were conducted for the SAR arc brightness and for the background airglow generated by chemical recombination.

The SAR arc observed on March 22, 1990, lay just poleward of the Millstone Hill Observatory throughout the evening sector, permitting the radar to sample altitude profiles of the ionospheric temperatures and density associated with the arc. The ionospheric features were magnetic field aligned, and the narrow radar beam penetrated the perturbed region at different altitudes in several local radar beam positions. Composite profiles through the arc have been constructed by sorting the local data between magnetic latitudes $55.5^{\circ}$ and $56.5^{\circ}$. In addition, ionospheric conditions immediately equatorward of the SAR arc were constructed to illustrate background airglow conditions. Modeling has been done for conditions at $0340 \mathrm{UT}$, the time of the DMSP overflight. In addition, the radargenerated profiles are most representative of conditions near the arc at that time.
In Figure 6a, the observed 630.0-nm emission intensities along the meridian are shown with a to uncertainty indicated by the shading. The modeling results shown in Figure $6 c$ are indicated by symbols. The van Rhijn (slant ray path) effect from the background airglow layer has been removed from the data, and thus the increase in airglow intensity seen to the south reflects the electron density latitude gradient shown in Figure 2a. Diffuse auroral emission features north of the SAR arc are not shown. In Figure 6b, the ion and electron temperature profiles observed with the radar both inside and outside the arc are presented along with the MSIS-92 neutral temperatures, while on the right side of Figure $6 \mathrm{c}$ the corresponding electron density profiles are given. As seen from Figures $6 b$ and $6 c$, electron temperatures within the arc increased by at least a factor of 2 over those at adjacent latitudes at altitudes above $250 \mathrm{~km}$, while the electron density decreased by a factor of 10 . The ion temperature was only weakly enhanced (from $1800^{\circ} \mathrm{K}$ to $2200^{\circ} \mathrm{K}$ ) within the arc at the time of the detailed local observations $(0300-0600$ UT). This increase is consistent with that expected due to ion/neutral collisions for the $800-\mathrm{m} / \mathrm{s}$ sunward velocity observed [StMaurice and Hanson, 1982]. The resultant model airglow and SAR 630.0-nm volume emission rate profiles are given at the left in Figure $6 c$, with column-integrated emission results for airglow and the SAR arc indicated by the symbols in Figure 6a.

Within the context of this paper, the background airglow simulations south of the SAR arc are within acceptable range of the
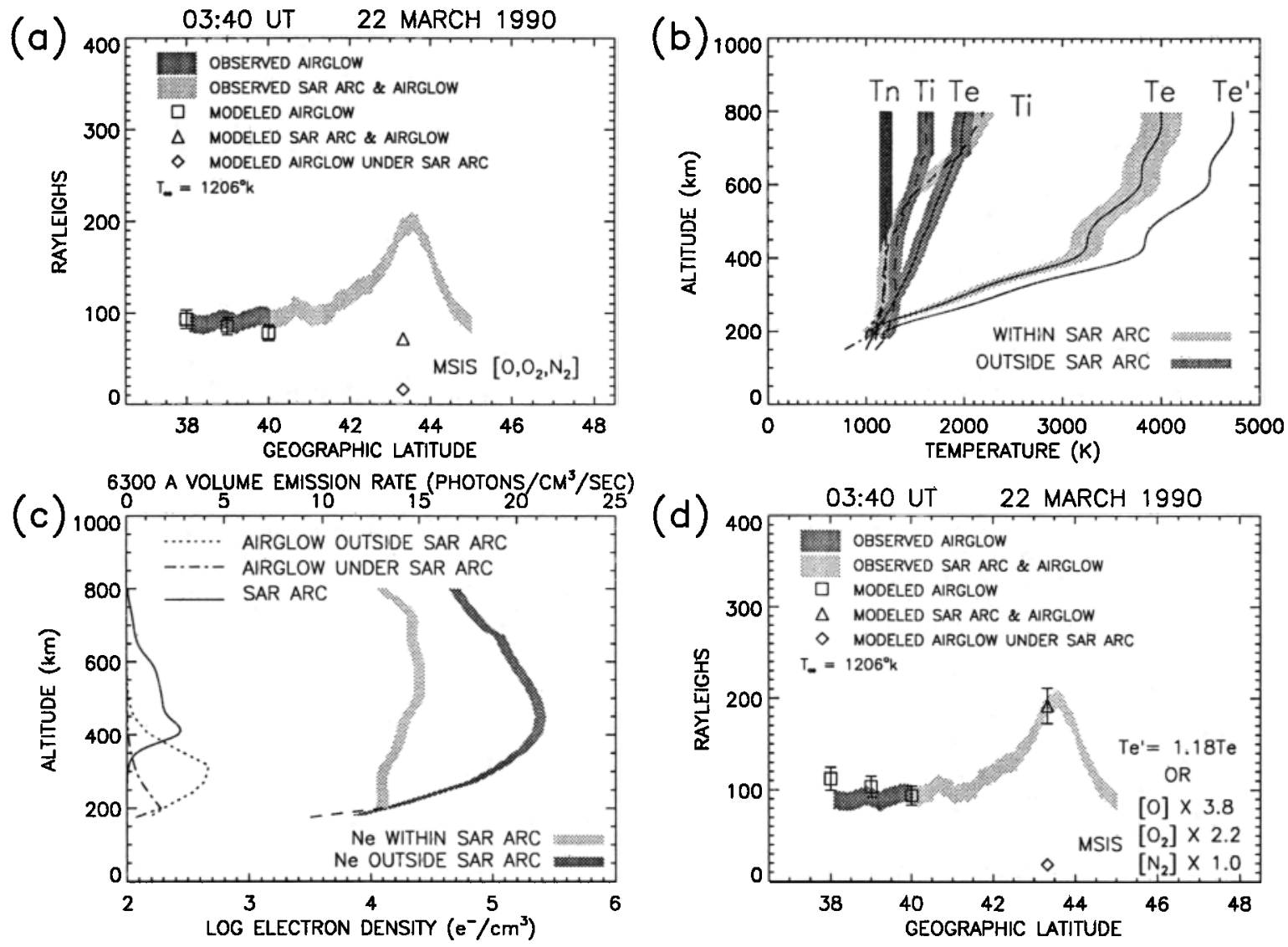

Figure 6. (a) Observed 630.0-nm emission intensities along the Millstone meridian along with a to uncertainty indicated by the shading. Predictions of the modeling results (shown in Figure 8c) are indicated by symbols for the latitude of the SAR arc and at three positions equatorward of the arc. (b) Ion and electron temperature profiles observed with the radar both inside and outside the arc, along with MSIS ' 92 neutral temperatures. Profile $T_{\varepsilon}$ ' represents an $18 \%$ increase from the observed most probable SAR arc temperature profile. (c) Corresponding electron density profiles (right side), and the model airglow and SAR 630.0-nm volume emission rate profiles (left side). (d) Model results for changes in the MSIS neutral constituents or using the enhanced $T_{e}^{\prime}$ profile, both of which yield a good fit to both the airglow and SAR arc emission levels. 
observations. Modeling for the position of the arc, using standard assumptions, underestimates the SAR arc intensity, however. Airglow from the trough is computed to be $\sim 20 \mathrm{R}$, and the SAR arc model results add an additional $65 \mathrm{R}$. The shortfall of $\sim 145 \mathrm{R}$ suggests that there could be either a precipitation component to SAR arc generation via electrons (as suggested by Slater et al. [1987]) or ions (as suggested by Mendillo et al. [1987]). The DMSP ion measurements shown in Figure 1 support the notion of a small 630.0$\mathrm{nm}$ enhancement associated with an ion precipitation region. The modeled emission intensity of the SAR arc is highly dependent on the electron temperature profile used, and it is possible that the profile observed by the radar and used by the model underestimates the enhancement associated with the arc. Alternatively, the MSIS composition under $K p=4+$ conditions might be wrong in this case, or photochemical cross sections could be in error.

In order to address the difference between the observed SAR arc intensity and the model prediction when using our best estimate of the ambient parameters, we have tried several variants of the ion and neutral parameters and have rerun the model. Figure $6 \mathrm{~d}$ illustrates modeling results done using variations in electron temperature or MSIS parameters that yield a best fit to both the background airglow and the SAR arc emission levels. An increase in the electron temperature profile by $18 \%$ above the most probable radar estimate (curve labeled $T_{e}{ }^{\prime}$ in Figure $6 c$ ) more closely reproduces the emission intensity observed in the arc. The maximum temperatures observed by the radar at each altitude during the interval of observations in the vicinity of the SAR arc are in good agreement with the profile, $T_{e}^{\prime}$, suggesting that these higher temperatures better characterize the arc. Changes in the MSIS neutral composition also yield an increased arc emission intensity, and factor of 2 increases in $\left[\mathrm{O}_{2}\right]$ and 4 in [O] result in a modeled arc intensity in keeping with the observations, independent of the $18 \%$ enhancement in $T_{e}$ or the effects of particle precipitation. Such deviations from the standard MSIS values are, perhaps, not unreasonable under disturbed conditions. However, the results of Buonsanto et al. [1992b] indicate that [O] may have been depleted at this time, instead of enhanced. In the case reported here, the actual need for a nonthermal mechanism for the "SAR arc deficiency" is not as clearly demonstrated as occurred for the event of November 14, 1984 [Mendillo et al., 1987]. The several possibilities of the effects of precipitation, a further enhancement of $T_{e}$ beyond that actually observed, and uncertainties in cross section are still open and could have contributed to the difference between observed and modeled SAR arc emission intensity.

\section{Discussion}

\section{Relationship to SAID}

A distinctive feature of the event we have described is the close association of the SAR arc with a persistent region of moderately strong sunward plasma convection. The magnitude and location of this convection qualify it to be considered a (SAID) event, as first observed by Galperin et al. [1974]. Previous studies have not found a relationship between subauroral ion drifts and SAR arcs, although both phenomena are known to occur near the same geophysical location. A SAID event is defined as westward convection with magnitude in excess of $500 \mathrm{~m} \mathrm{~s}^{-1}$, equatorward of the auroral precipitation, and often associated with an ionospheric trough [Spiro et al., 1979]. Providakes et al. [1989] describe detailed observations of SAID with the Millstone Hill radar, including the close association of enhanced convection electric field $\left(>50 \mathrm{mV} \mathrm{m}^{-1}\right)$ with a deep, $1^{\circ}$-wide, ionospheric trough. SAID are associated with dis- nurbed conditions, and specifically with substorm recovery [Anderson et al., 1993], while SAR arcs are thought to be longerlived and associated with ring-current phenomena. Our long-duration observation of the characteristics of a SAID event is a unique feature of the event we have described.

In the theoretical treatment of Southwood and Wolf [1978], a northward electric field and rapid sunward convection at subauroral latitudes are created by the penetration of disturbance-injected partial ring current ions to a lower $L$ shell than the plasma sheet electrons. The strength of this electric field is inversely related to the latitudinal separation of the particle boundaries. Yeh et al. [1991] investigated the double-peaked westward convection feature characteristic of the March 22, 1990, event and found just such a separation between the electron and ion equatorward boundaries associated with the region of subauroral convection. Anderson et al. [1991] found that all SAD events observed at MLT $<22$ hours occurred in the equatorward portion of such a double-peaked sunward convection pattern. Our observation that the CPS electrons extended equatorward to the poleward edge of the SAID convection and SAR arc on March 22, 1990, while an ion precipitation feature was located at its equatorward edge, is also consistent with a separation of the ion and electron equatorward penetration boundaries and with the mechanism proposed by Southwood and Wolf [1978]. Anderson et al. [1993] suggest that the intense poleward directed electric fields characteristic of SAID are a result of the low Pedersen conductance in the region, and that frictional heating driven by such fields acts to further reduce the conductance through enhanced recombination [Schunk et al., 1976] and ion outflow [Yeh and Foster, 1990] and thus to increase the electric field strength and deepen the ionospheric trough even more.

Anderson et al. [1991] discuss evidence for the existence of fossil SAID, regions of residual enhanced sunward convection related to prior SAID intensifications. Evans et al. [1983] described similar fossil ionospheric troughs, often seen from Millstone Hill following a previous enhancement of the convection electric field which could have resulted in the trough formation through the processes of enhanced recombination or advection from the nightside. The observations presented in this paper provide evidence for the close spatial and temporal association of the SAR arc with SAID events and the fossil (convection-related) ionospheric trough. The characteristics of these three types of subauroral phenomena reflect magnetospheric processes occurring on field lines threading the plasmapause, the enhanced ring current, and the inner edge of the plasma sheet. Their close association at low altitudes indicates the interrelationship of the magnetospheric processes which produce them.

The SAR arc/SAD relationship we have found has not been reported in previous studies, and this may be the case because conditions are not appropriate for SAR arc formation in association with the more intense $\left(v>2 \mathrm{~km} \mathrm{~s}^{-1}\right)$ SAID events which occur when the ion and electron penetration boundaries are closer together [Southwood and Wolf, 1978]. Few prior studies, however, have had the capability of investigating both the $630.0-\mathrm{nm}$ emission and plasma convection and thus of commenting on a SAID/SAR arc association. It is possible that the relationship we have observed between the SAR arc occurrence and location and the SAID is fortuitous and that each phenomenon is related to separate features and conditions in the magnetosphere-ionosphere system which happen to coincide during the March 22, 1990, event. A reexamination of several previously published events, however, supports the SAR arc/SAID relationship we report here.

The optical/radar study of Mendillo et al. [1987] clearly showed the SAR arc/trough association, but did not report any associated 
enhancement in the convection velocity. Millstone Hill azimuth scan data for that event (unpublished) show that the faint, morningsector SAR arc (04 MLT) was colocated with a $3^{\circ}$-wide residual region of $250 \mathrm{~m} \mathrm{~s}^{-1}$ westward convection, situated equatorward of the $500 \mathrm{~m} \mathrm{~s}^{-1}$ eastward (sunward) convection at auroral latitudes. Providakes et al. [1989] investigated radar, optical, and satellite observations of SAID during intense storm conditions. The SAID event they discussed at 0300 UT on April 21, 1985, for which redline images were available, occurred just equatorward of the imager field of view, and no associated 630.0-nm emission was reported, although an imager frame at the end of their data coverage showed a detached $630.0-\mathrm{nm}$ feature some $6^{\circ}$ equatorward of the regular auroral enhancement and colocated with the deep trough and SAID ( $>500 \mathrm{~m} \mathrm{~s}^{-1}$ ) convection. A companion paper by Mendillo et al. [1989a] showed a detached 630.0 -nm arc at $L=2.7$, some 2 hours prior to the SAID event interval. A reexamination of the Millstone Hill radar data taken at that time finds that this arc was centered in a deep plasma trough and associated with westward convection velocities of $>700 \mathrm{~m} \mathrm{~s}^{-1}$. We conclude that these earlier Millstone Hill observations also indicate that SAR arcs are associated with a discrete region of rapid westward convection and a fossil trough/ SAID, thus supporting the findings of this study.

\section{Signatures of Field-Aligned Currents}

Rich et al. [1980] found net downward field-aligned currents of up to $1 \mu \mathrm{A} \mathrm{m}^{-2}$ across the region of SAID and associated a portion of the topside density depletion in such regions with the outflow of thermal electrons carrying this current. They note that as the topside is depleted, the differential drift between electrons and ions that supports the current must increase until threshold conditions for plasma instability are exceeded. Such a mechanism was suggested by Foster [1988] in order to explain the occurrence of strongly enhanced ion acoustic waves and radar backscatter from the vicin-

ENHANCED BACKSCATTER SPECTRA

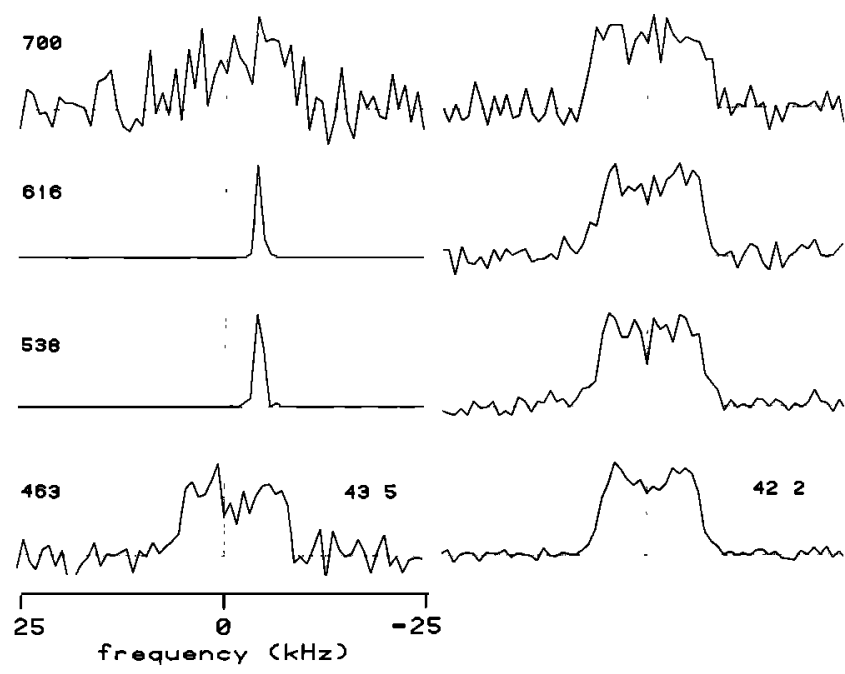

Figure 7. Backscatter radar spectra at four altitudes from the position of the SAR arc which display an ion-acoustic enhancement characteristic of a field-aligned current carried by upward streaming thermal electrons [cf. Foster et al., 1988]. Spectra are normalized so that the power level at the peak frequency reads full scale. To the left are shown perturbed spectra near $600 \mathrm{~km}$ altitude at the $43.5^{\circ}$ latitude position of the SAR arc, while at the right are unperturbed spectra near $42^{\circ}$. ity of the trough. Enhancel radar echoes of the type first reported by Foster et al. [1988] were recorded during the March 22, 1990. event from the position of the SAR arc and trough/convection feature and examples of the enhanced ion acoustic spectra observed are presented in Figure 7. The average current density calculated for the region in this event, $0.8 \mu \mathrm{A} \mathrm{m}^{-2}$, is comparable to that reported by Rich et al. [1980], and filamentary intensification of the downward current and the ensuing plasma wave instability could lead to the backscatter signature observed. This observation suggests that the currents and mechanisms associated with SAID contribute to the frequent occurrence of enhanced ion acoustic spectra near the equatorward edge of the trough as reported by Foster et al. [1988].

The observations of Shepherd et al. [1980] during the massive storm of August 1972, are of interest, since they locate an intense SAR arc within a region of upward field-aligned current. The arc intensity and the scanning photometer used permitted the separation of the 630.0-nm emission into two regions: a lower region stimulated by the soft electron precipitation associated with the FAC and an upper region, near $450 \mathrm{~km}$, which they associate with the more normal heat flux excitation. In situ Langmuir probe observations found a narrow ( $<1 \mathrm{~km}$ wide) topside ionospheric depletion at the center latitude of the SAR arc emission. No such ionospheric cavity was found at the time of the detailed DMSP F9 observations shown in Figure 1a, but the existence of such a feature could be related to rapid thermal electron vertical drift and enhanced plasma processes, of the type leading to the backscatter enhancement shown in Figure 7. Foster et al. [1988] suggested that such processes are short-lived and sporadic on field lines near the trough.

Acknowledgments. Millstone Hill radar operations and analysis are supported by National Science Foundation Co-operative Agreement ATM9102445 to the Massachusetts Institute of Technology. The Millstone CEDAR $630.0 \mathrm{~nm}$ imager is supported by National Science Foundation Grants ATM-9012786 and ATM 9203198 to Boston University. DMSP analysis and work at Phillips Laboratory are supported in part by Task 2311 G5 of the Air Force Office of Scientific Research.

The Editor thanks G. G. Shepherd and P. C. Anderson for their assistance in evaluating this paper.

\section{References}

Anderson, P. C., R. A. Heelis, and W. B. Hanson, The ionospheric signatures of rapid subauroral ion drifts, J. Geophys. Res., 96, 5785-5792, 1991.

Anderson, P. C., W. B. Hanson, R. A. Heelis, J. D. Craven, D. N. Baker, and L. A. Frank, A proposed production model of rapid subauroral ion drifts and their relationship to substorm evolution, J. Geophys. Res., 98, 6069$6078,1993$.

Baumgardner, J., and S. Karandanis, CCD imaging system uses video graphics controller, Electron. Imaging, 3, 28, 1984.

Buonsanto, M. J., J. C. Foster, and D. P. Sipler, Observations from Millstone Hill during the geomagnetic disturbances of March and April 1990, $J$. Geophys. Res., 97, 1225-1243, 1992a.

Buonsanto, M. J., Y.-K. Tung, and D. P. Sipler, Neutral atomic oxygen density from nighttime radar and optical measurements at Millstone Hill, J. Geophys. Res., 97, 8673-8679, $1992 \mathrm{~b}$.

Evans, J. V., J. M. Holt, W. L. Oliver, and R. H. Wand, The fossil theory of nighttime high-latitude $F$ region troughs, J. Geophys. Res., 88, 7769, 1983.

Foster, J. C., Plasma turbulence and enhanced UHF radar backscatter from the topside ionosphere, Physics of Space Plasmas, edited by T. Chang, pp. 213-229, Scientific, Cambridge, Mass., 1988.

Foster, J. C., C. del Pozo, K. Groves, and J.-P. St-Maurice, Radar observations of the onset of current-driven instabilities in the topside ionosphere, Geophys. Res. Lett., 15, 160-163, 1988. 
Galperin, Y., V. N. Ponomarev, and A. G. Zosimova, Plasma convection in the polar ionosphere, Ann. Geophys., 30, 1-7, 1974.

Greenspan, M. E., P. B. Anderson, and J. M. Pelagatti, Characteristics of the thermal plasma monitors (SSES) for the Defense Meteorological Satellite Program (DMSP) spacecraft S8 through F10), Tech. Rep. AFGL-TR-86-0227, Air Force Geophys. Lab., Hanscom AFB, Mass., 1986.

Hedin, A. E., MSIS-86 thermospheric model, J. Geophys. Res., 92, 4649 4662, 1987.

Hoch, R. J., and J. Lemaire, Stable auroral red arcs and their impcrtance for the physics of the plasmapause region, Ann. Geophys., 31, 105-110, 1975.

Kozyra, J. U., E. G. Shelley, R. H. Comfort, L. H. Brace, T. E. Cravens, and A. F. Nagy, The role of ring current $\mathrm{O}^{+}$in the formation of stable auroral red arcs, J. Geophys. Res., 92, 7487-7502, 1987.

Mendillo, M., J. Baumgerdner, J. Aarons, J. Foster, and J. Klobuchar, Ground-based imaging of detailed arcs, ripples in the diffuse aurora, and patches of 6300 A emission, Ann. Geophys., 5A, 543-550, 1987.

Mendillo, M., J. Baumgardner, and J. Providakes, Coordinated optical and radio studies of ionospheric disturbances: Initial results from Millstone Hill, J. Geophys. Res., 94, 5367-5381, 1989a.

Mendillo, M., J. Baumgardher, and P. J. Sultan, Optical and radar techniques applied to chemical release "active experiments" in the ionosphere thermosphere system, in WITS Handbook, vol. II, edited by C. H. L.iu, pp. 250 ff., SCOSTEP, University of Ilinois, Urbana, 1989b.

Providakes, J. F., M. C. Kelley, W. E. Swartz, M. Mendillo, and J. M. Holt, Radar and optical measurements of ionospheric processes associated with intense subauroral electric fields, J. Geophys. Res., 94, 5350-5366, 1989.

Rees, M. H., and R. G. Roble, Observations and theory of the formation of stable auroral red arcs, Rev. Geophys. Space Phys. Sci., 13, 201-242, 1975.

Rich, F. J., and M. Hairston, Large-scale convection patterns observed by DMSP, J. Geophys. Res., in press, 1994.

Rich, F. J., W. J. Burke, M. C. Kelley, and M. Smiddy, Observations of field- aligned currents in association with strong convection electric fields at subauroral latitudes, J. Geophys. Res., 85, 2335-2340, 1980.

Schunk, R. W., P. M. Banks, and W. J. Reitt, Effects of electric fields and other processes upon the nighttime high-latitude $F$ layer, $J$. Geophys. Res., 80, 3121, 1976.

Shepherd, G. G., L. H. Brace, J. R. Burrows, J. H. Hoffiman, H. G. James, D. M. Klumper, A. F. Nagy, E. Stathopoulos, and J. H. Whitteker, An unusual SAR arc observed during ring current development, 4 August, 1972, Planet. Space Sci., 28. 69, 1980.

Slater, D. W., C. Gurgilio, J. U. Kozyra, E. W. Kleckner, and J. D. Winningham, A possible energy source to power stable auroral red arcs: Precipitating electrons, J. Geophys. Res., 92, 4543-4552, 1987.

Southwood, D. J., and R. A. Wolf, An assessment of the role of precipitation in magnetospheric convection, J. Geophys. Res., 83, 5227-5232, 1978.

Spiro, R. W., R. A. Heelis, and W. B. Hanson, Rapid subauroral ion drifts observed by Atmospheric Explorer C, Geophys. Res. Lett., 6, 657-660, 1979.

St-Maurice, J. P., and W. B. Hanson, Ion frictional heating at high latitudes and its possible use for an in situ determination of neutral thermospheric winds and temperature, J. Geophys. Res., 87, 7580-7602, 1982.

Yeh, H.-C., and J. C. Foster, Storm-time heavy ion outflow at mid-latitude, J. Geophys. Res., 95, 7881-7891, 1990.

Yeh, H.-C., J. C. Foster, F. J. Rich, and W. Swider, Storm-time electric field penetration observed at mid-latitude, J. Geophys. Res., 96, 5707-5721, 1991

M. J. Buonsanto and J. C. Foster, Haystack Observatory, Massachusetts Institute of Technology, Route 40, Westford, MA 01886.

W. Denig and F. J. Rich, Geophysics Division, Phillips Laboratory, Hanscom AFB, MA 01731.

M. Mendillo and D. Nottingham, Astronomy Department, Boston University, Boston, MA 02215.

(Received May 18, 1993; revised October 19, 1993; accepted October 28, 1993.) 